\title{
Effect of ultrasound-guided proximal and distal approach for obturator nerve block in transurethral resection of bladder cancer under spinal anesthesia
}

Cancer Management and Research

\section{Chao $\operatorname{Han}^{1,2, *}$ \\ Tieliang $\mathrm{Ma}^{1,2, *}$ \\ Daoyun Lei ${ }^{1}$ \\ Songhui Xie' \\ Zhijun $\mathrm{Ge}^{1,2}$}

'Department of Anesthesiology, The Affiliated Yixing Hospital of Jiangsu University, Yixing, Jiangsu, People's Republic of China; ${ }^{2}$ Yixing Clinical College, Medical College of Yangzhou University, Yixing, Jiangsu, People's

Republic of China

*These authors contributed equally to this work
Correspondence: Chao Han

Department of Anesthesiology, The Affiliated Yixing Hospital of Jiangsu University, 75 Tongzhenguan Road, Yixing, Jiangsu 214200, People's Republic of China

Tel $+865108792 \quad 1196$

Fax +865108792 III0

Email staff940@yxph.com
Background: Ultrasound-guided proximal or distal approach for obturator nerve block is preformed to prevent adductor muscle spasm during transurethral resection of bladder tumors. The aim of the study was to compare the effectiveness of two different techniques in blocking the obturator nerve during transurethral resection of a bladder tumor.

Methods: Fifty obturator nerve blocks were performed for transurethral bladder tumor resection and divided into two groups. One group received ultrasound-guided proximal obturator nerve block approach (proximal group), and the other group received ultrasoundguided distal obturator nerve block approach (distal group). Grade of adductor muscle spasm, the rate of clinical effectiveness, duration of block procedure, and complications were recorded. Patients with grade two adductor spasms were transferred to general anesthesia.

Results: Two patients in the distal group and one in the proximal group were transferred to general anesthesia for severe adductor muscle spasms. No difference was found in clinical effectiveness rate of obturator nerve block between the two groups. differed insignificantly. The number of patients who had no adductor muscle spasms in the proximal group was significantly higher than that of the distal group. Vascular puncture was detected in two patients in the proximal group and one patient in the distil group. No other complications were observed.

Conclusion: No difference was found for clinical effectiveness between the two groups. However, vascular puncture should receive more attention.

Keywords: ultrasound-guided proximal, obturator nerve block, tans-urethral resection of the bladder tumor

\section{Introduction}

Bladder cancer is a highly prevalent disease, and transurethral resection of a bladder tumor still represents the most appropriate and effective treatment for transitional cell carcinoma of the bladder and provides essential histopathologic information necessary for definitive diagnosis, staging, and primary treatment. ${ }^{1}$ However, the electrical stimulation directly adjacent to the lateral wall of the bladder may induce the obturator nerve reflex and sudden adductor muscle contraction, which may cause incomplete tumor resection, bladder perforation, extravesical dissemination of the cancer cells, and even injury to the obturator artery. ${ }^{2-4}$ It has been reported that the incidences of sudden thigh movement and bladder perforation during 
surgical procedure in the absence of obturator nerve block were $49 \%$ and $16 \%$ respectively. ${ }^{5}$ Therefore, an obturator nerve block is essential and critical to ensure effective and safe transurethral resection of the bladder tumor. ${ }^{6}$

Various approaches have been proposed to accomplish obturator nerve block, including traditional surface landmarks with or without nerve stimulation to localize the obturator nerve. Along with the technological advances in ultrasonographic application during the last decade, many ultrasoundguided obturator nerve block approaches have been reported and can be classified as distal or proximal. In the distal approach, the anterior and posterior branches of the obturator nerve are blocked separately by two injections of local anesthetic (LA) directed toward the interfacial plane between the pectineus and adductor brevis muscles and the plane between the adductor longus and adductor brevis muscles. ${ }^{7-9}$ The proximal approach, involving several transducer positions, is defined as a single injection of LA into the interfacial plane between the pectineus and obturator externus muscles. ${ }^{10-13}$ It is generally believed that the distal approach could not prevent an adductor muscle spasm during transurethral resection of a bladder tumor even if an obturator nerve block is correctly performed, and the proximal approach may be superior for providing successful blockade of the obturator nerve. ${ }^{14}$ However, there is not enough clinical evidence to support this point.

We conducted a randomized, controlled trial to compare the effectiveness of the two approaches in patients undergoing transurethral resection of lateral bladder wall tumor.

\section{Methods}

\section{Patients}

In this prospective, randomized study, we enrolled 50 patients, aged 50-80 years. Allocation of patients receiving either distal (distal group) or proximal approach (proximal group) was performed using a computer-generated randomization scheme. Approval of the study was obtained from the ethics committee of the affiliated Yixing Hospital of Jiangsu University and written informed consent was obtained from each of the participants. This study was conducted in accordance with the Declaration of Helsinki.

\section{Inclusion criteria and exclusion criteria}

All patients met American Society of Anesthesiologists physical classification classes I-III, were scheduled for unilateral transurethral resection of lateral bladder wall tumor under spinal anesthesia and required obturator nerve block. Patients with a known allergy to LAs, inguinal lymphadenopathy, infection or scars at the needle insertion site, coagulopathy, and neuromuscular disorders were excluded. All patients participated in the current study.

\section{Sample size calculation}

We calculated the sample size prior to the implementation of the study. We calculated the sample size by using a power and sample size program. ${ }^{15}$ According to existing literature. ${ }^{16}$ In their study the pain scores out of 10 was 5.4. We considered a pain score reduction of at least 1.5 as clinically significant. If the mean of Cohort 1 was 5.4, the mean of Cohort 2 was 3.9 and assuming an SD of 2.4, the required sample size in each cohort is 42 with a power of $80 \%$. The significance level was set at $\alpha=0.05$. Thus, our study recruited 50 patients in each group to meet the requirement of sample size.

\section{Procedure}

On arrival to the operating room, intravenous access was established, and the patients received noninvasive blood pressure monitoring, electrocardiography using lead II and pulse oximetry monitoring. Spinal anesthesia was performed with $10-15 \mathrm{mg} 0.5 \%$ hyperbaric bupivacaine by $25 \mathrm{G}$ Quincke needle at L3-4 or L2-3 space with patients in lateral position (a single anesthesiologist). Afterwards, patients were immediately placed into the supine position. We observed the patients for 10 minutes to ensure hemodynamic stability and used a pinprick test to determine the sensory level block reached above T10, which blocks conduction in the sensory nerve fibers of the bladder. Then, obturator nerve block was performed by another experienced investigator.

Patients were in supine position with the thigh slightly abducted and externally rotated. The skin was prepared and draped in a sterile fashion, and the linear 5- to $10 \mathrm{MHz}$ ultrasound transducer was enclosed in a sterile sleeve. In the distal group, the transducer was placed medial to the femoral vein, along the inguinal crease, perpendicular to the skin. After identification of the pectineus, adductor longus, adductor brevis, and adductor magnus muscles through the classic $\mathrm{Y}$ shape, a $21 \mathrm{G}$ needle was advanced in lateral-to-medial direction under in-plane ultrasound guidance to position the needle tip at a hyperechoic structure of the fascial interface between the adductor longus and adductor brevis muscles. After negative aspiration, $5 \mathrm{~mL}$ of ropivacaine $0.5 \%$ was injected. Then, the needle tip was advanced and positioned between the adductor brevis and adductor magnus muscles, and $5 \mathrm{~mL}$ of $0.5 \%$ ropivacaine was injected (Figure 1). In group P, the transducer was placed on the medial aspect of the inguinal crease and then 
tilted 40-50 degrees cranially until a hyperechoic structure deep and lateral to the pectineus (the inferior margin superior pubic ramus) was visualized, as described by Lin et al. ${ }^{13}$ After identification of the intermuscular fascia deep to the pectineus muscle separating it from the obturator externus muscle, a needle was inserted into this fascia under in-plane ultrasound guidance in an inferior-to-superior direction and $10 \mathrm{~mL}$ of $0.5 \%$ bupivacaine was then slowly injected (Figure 2 ). The LA solution spread was monitored under real-time visualization.

\section{Outcome assessment}

The transurethral resection of the bladder tumor was performed by the same urologist team using a 26-Fr monopolar resectoscope (Excel 350 MCDS, Italy) with 30 degree optic and glycerol irritant solution 15 minutes following injection. Severity of adductor muscle spasm was evaluated by the urologist who was blinded to the obturator nerve block approach used. The motor block was classified as the following: grade $0=$ no adductor muscle contraction, grade $1=$ slight adductor muscle contraction which would not disturb the surgery, and grade $2=$ severe adductor muscle contraction which would prevent the surgery. Grade 0 and 1 were both considered clinically effective. Patients with grade 2 adductor spasms during operations were transferred to general anesthesia with administration of non-depolarizing muscle relaxants. Duration of block procedure and complications, such as LA intonation, vascular puncture, hematoma, nerve injury, and visceral injury, if any, were also recorded.

\section{Statistical analysis}

Data were expressed as the mean \pm SD for age, height, weight, operation, and duration of block procedure. Independent sample unpaired $t$-test was applied for comparison of age, height, weight, operation, and duration of block procedure in normal distributions, and Mann-Whitney U tests were performed for

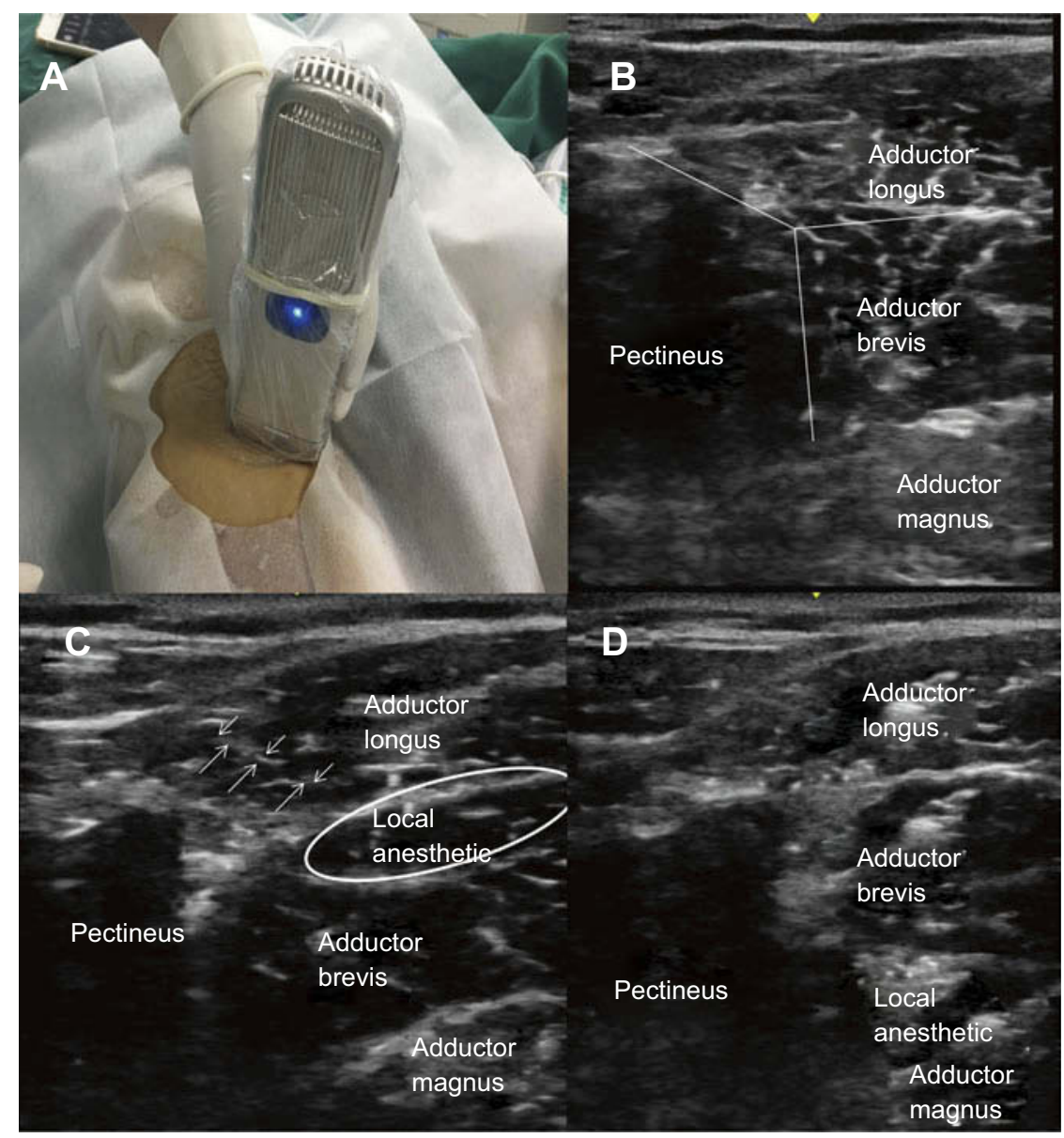

Figure I Ultrasound-guided distal obturator nerve block. (A) Patient is in supine position with the thigh slightly abducted and externally rotated. The transducer is placed perpendicularly just below the inguinal ligament. (B) The pectineus, adductor longus, adductor brevis, and adductor magnus muscles are identified and $Y$ shape is visualized. (C) A needle is in an advanced lateral-to-medial direction using in-plane ultrasound guidance until the needle tip is positioned at fascial interface between the adductor longus and adductor brevis muscles, then local anesthetic is injected. (D) Local anesthetic is injected between adductor brevis muscles and adductor magnus. 


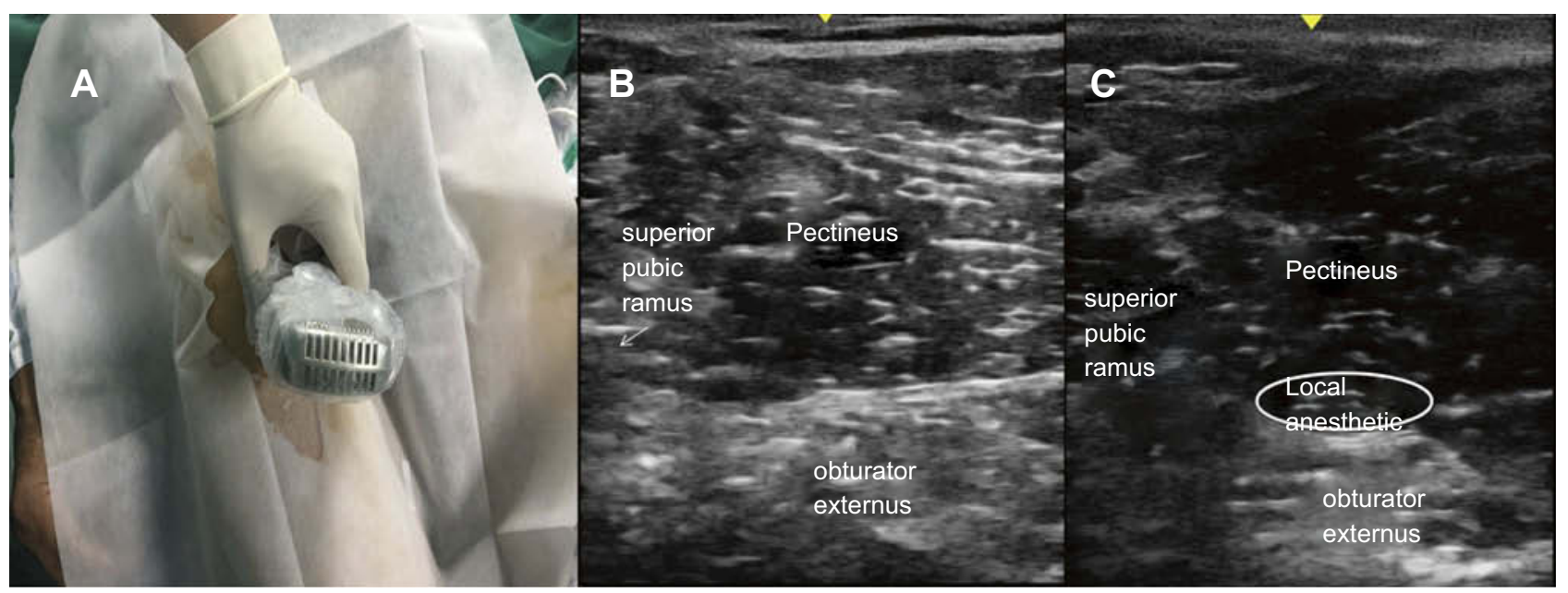

Figure 2 Ultrasound-guided proximal obturator nerve block. (A) Patient is in supine position with the thigh slightly abducted and externally rotated. The transducer is placed on the medial aspect of the inguinal crease and then tilted 40-50 degrees cranially. (B) The superior pubic ramus, the pectineus, and obturator externus muscles are defined. (C) A needle is inserted into the fascial interface plane between pectineus and obturator externus using in-plane ultrasound guidance in a lateral-to-medial direction, then local anesthetic is injected.

continuous ASA score. Chi-squared tests were performed for gender, site of obturator nerve block, and complications. All statistical analysis was performed by SPSS 16.0 (SPSS, Inc., Chicago, IL, USA). A $P$-value less than 0.05 was considered statistically significant.

\section{Results}

Demographics of patients are presented in Table 1. There were no significant differences in duration of operation or duration of block procedure between the two groups. Figure 3 shows the efficacy of obturator nerve block in

Table I Characteristics of subjects included

\begin{tabular}{|c|c|c|c|}
\hline & Proximal group & Distal group & $P$-value \\
\hline Age (years) & $64.1 \pm 6.3$ & $65.1 \pm+6.2$ & 0.57 \\
\hline \multicolumn{4}{|l|}{ Gender } \\
\hline Male & 22 & 23 & 0.63 \\
\hline Female & 3 & 2 & \\
\hline Height $(\mathrm{cm})$ & $167.2 \pm 6.7$ & $167.6 \pm 7.1$ & 0.82 \\
\hline Weight (kg) & $68.8 \pm 8.7$ & $69.5 \pm 8.1$ & 0.77 \\
\hline \multicolumn{4}{|l|}{ ASA score } \\
\hline I & 2 & 4 & 0.58 \\
\hline II & 17 & 17 & \\
\hline III & 6 & 4 & \\
\hline \multicolumn{4}{|l|}{ Site of obturator nerve block } \\
\hline Right & 14 & 12 & 0.57 \\
\hline Left & 11 & 13 & \\
\hline Duration of operation & $33 \pm 8.9$ & $34 \pm 9.6$ & 0.71 \\
\hline Duration of block procedure & $8.5 \pm 1.7$ & $8.9 \pm 2.2$ & 0.47 \\
\hline \multicolumn{4}{|l|}{ Complications } \\
\hline Local anesthetic intonation & 0 & 0 & 1.0 \\
\hline Vascular puncture & 2 & 1 & 0.99 \\
\hline Hematoma & 0 & 0 & 1.0 \\
\hline Nerve injury & 0 & 0 & 1.0 \\
\hline Visceral injury & 0 & 0 & 1.0 \\
\hline
\end{tabular}

Abbreviation: ASA, American society of Aneshesiologists physical status classification. 


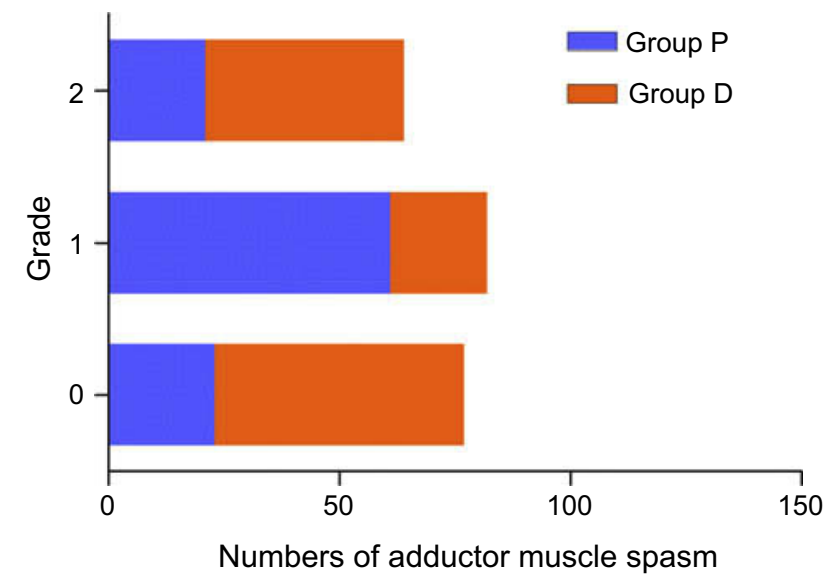

Figure 3 Number of different adductor muscle spasms in both groups.

the two groups. Two patients in the distal group were transferred to general anesthesia for severe adductor muscle spasm, and one patient in the proximal group. The clinical effectiveness rate of obturator nerve block was not significantly different. The number of patients who had no adductor muscle spasm was significantly higher in the proximal group than that of the distal group. Vascular puncture was detected in two patients in the proximal group and in one patient in the distal group. No other complications were observed.

\section{Discussion}

As we know, in almost all previous studies, the obturator nerve block was performed before spinal anesthesia to avoid the impact of lower limb motor nerve block. The obturator nerve provides no cutaneous innervation; therefore, we cannot use a lack of sensory block to determine whether an obturator nerve block is effective. The success of obturator nerve block is generally evaluated by confirming a decrease from baseline to block placement in adductor muscle strength using a sphygmomanometer, as described by Lang et al. ${ }^{17}$ However, obturator nerve block prior to spinal anesthesia inevitably causes pain and discomfort, even in the presence of LA infiltration, which decreases patient satisfaction. In our study, the obturator nerve block was designed to be performed after the confirmation of spinal anesthesia effect, which reduced panic and discomfort and increased patient satisfaction. We evaluated the effect of obturator nerve block according to adductor muscle spasm during transurethral resection of bladder tumor procedure and ensured surgical safety by changing the anesthesia technique in a timely fashion. We found that both approaches had similar clinical effectiveness in this study, suggesting a feasible alternative for obturator nerve block.

We also found that the incidence of 0 adductor muscle contractions in group $\mathrm{P}$ was significantly higher than that of group D, which indicated that the proximal approach may be superior to the distal approach. The main problem with the distal approach is the highly variable distribution pattern of the anterior branch, and at least two injections with a minimum volume incomplete spread of LA to the nerve. ${ }^{10}$ In contrast, the proximal approach targets the common obturator nerve or its main branches and a larger LA volume ensures the nerve is completely covered. The anatomic characteristics explained the observation results in our study.

As mentioned previously, five approaches have been proposed in different literature and are summarized in Table 2. We adopted Lin's approach, a modified Taha's approach, to perform obturator nerve block based on three merits. First, the visibility of the thick hyperechoic fascia underneath the pectineus muscle is good, providing an extra soft tissue landmark in addition to the superior pubic ramus as the bony landmark. ${ }^{12}$ Second, placement of LA by ultrasound guidance and nerve stimulation techniques both rely on the needle tip being directed toward the nerve itself. The obturator nerve is difficult to electrically stimulate and image sonographically, however, an interfacial LA injection may achieve complete obturator nerve block without confirmation of electrical nerve stimulation. ${ }^{11}$ In addition, an in-plane approach monitored by color power Doppler may reduce the incidence of vascular puncture. The obturator artery and medial femoral circumflex artery and veins may be in close proximity to the obturator nerve at the level of blockade, ${ }^{18}$ even if there is no blood aspiration during this manipulation. We could try to avoid vascular puncture using ultrasound guidance, but complete prevention cannot be assumed. It might account for two vascular puncture patients in the proximal group.

There were two limitations in the current study. One possible limitation was the small sample size. In addition, no thigh adductor muscle contraction in 51 of $114(45 \%)$ transurethral resection inferolateral bladder tumor patients without obturator nerve block has been reported. ${ }^{19}$ The result indicates that not all resections uniformly stimulate a response, which may increase a false positive. A transresectoscope stimulation, designed by Mihara et al, ${ }^{20}$ which could predict the need to block the contraction of the thigh adductor during tumor resection, might decrease a false positive. 
Table 2 Comparison of the effect of ultrasound-guided proximal obturator nerve block techniques between the two groups

\begin{tabular}{|c|c|c|c|c|c|}
\hline & Anagnostopoulos et al & $\begin{array}{l}\text { Akkaya } \\
\text { et al }\end{array}$ & Taha & Lin et al & Yoshida et al. \\
\hline Body position & $\begin{array}{l}\text { Supine position hip slightly } \\
\text { abducted and externally } \\
\text { rotated }\end{array}$ & $\begin{array}{l}\text { Supine } \\
\text { position leg } \\
\text { straight }\end{array}$ & $\begin{array}{l}\text { Supine position } \\
\text { hip was } \\
\text { abducted and } \\
\text { externally } \\
\text { rotated }\end{array}$ & Supine position & Lithotomy position \\
\hline $\begin{array}{l}\text { Probe } \\
\text { position }\end{array}$ & $\begin{array}{l}\text { Perpendicular just below the } \\
\text { inguinal ligament, at the pubic } \\
\text { tubercle level, tilted cranially } \\
30^{\circ} \text { to } 40^{\circ}\end{array}$ & $\begin{array}{l}\text { Longitudinally } \\
\text { at the pubic } \\
\text { region }\end{array}$ & $\begin{array}{l}\text { Medial aspect of } \\
\text { the inguinal } \\
\text { crease, then } \\
\text { tilted cranially }\end{array}$ & $\begin{array}{l}\text { Medial aspect } \\
\text { of the inguinal } \\
\text { crease, then } \\
\text { tilted cranially }\end{array}$ & $\begin{array}{l}\text { Lateral to the perineum on the medial } \\
\text { aspect of the thigh along the extended } \\
\text { line of the inguinal crease and orien- } \\
\text { tated cephalad. }\end{array}$ \\
\hline $\begin{array}{l}\text { Needle } \\
\text { advance } \\
\text { technique }\end{array}$ & Out-of-plane & In-plane & Out-of-plane & In-plane & In-plane \\
\hline $\begin{array}{l}\text { Direction of } \\
\text { needle }\end{array}$ & Anterior to posterior & $\begin{array}{l}\text { Inferior to } \\
\text { superior } \\
\text { direction }\end{array}$ & $\begin{array}{l}\text { Anterior to } \\
\text { posterior }\end{array}$ & $\begin{array}{l}\text { Lateral to } \\
\text { medial }\end{array}$ & Anterior to posterior \\
\hline Landmarks & $\begin{array}{l}\text { FA FV } \\
\text { adductor muscle thick hyper- } \\
\text { echoic fascia }\end{array}$ & $\begin{array}{l}\text { Hyperechoic } \\
\text { area } \\
\text { SPR } \\
\text { PE }\end{array}$ & $\begin{array}{l}\text { PE } \\
\text { SPR } \\
\text { OE thick hyper- } \\
\text { echoic fascia }\end{array}$ & $\begin{array}{l}\text { PE } \\
\text { SPR } \\
\text { OE thick hyper- } \\
\text { echoic fascia }\end{array}$ & $\begin{array}{l}\text { ASIS } \\
\text { PE } \\
\text { SPR } \\
\text { OE hyperechoic fascia }\end{array}$ \\
\hline $\begin{array}{l}\text { Confirmation } \\
\text { with electrical } \\
\text { stimulation }\end{array}$ & Needed & Needed & Not needed & Not needed & Needed \\
\hline
\end{tabular}

Abbreviations: FA, femoral artery; FV, femoral vessels; SPR, superior pubic ramus; PE, pectineus muscle; OE, obturator externus-muscle; ASIS, anterior superior iliac spine.

\section{Conclusion}

In sum, the ultrasound-guided proximal and distil approach for obturator nerve block are both simple and successful alternative techniques for transurethral resection of lateral bladder wall tumors. The proximal approach provides a superior successful blockade of OB. In addition, vascular puncture should receive more attention.

\section{Acknowledgments}

This work was supported by fund of six best talent of Jiangsu, 2016 (WSW-113) and Jiangsu young medical talents (grant number QNRC2016209) and the fund of Clinical Science and Technology of Wuxi (grant number MS201609).

\section{Disclosure}

The authors report no conflicts of interest in this work.

\section{References}

1. DeGeorge KC, Holt HR, Hodges SC. Bladder cancer diagnosis and treatment. Am Fam Physician. 2017;96(8):507-514.

2. Tekgül ZT, Divrik RT, Turan M, Konyalioğlu E, Şimşek E, Gönüllü M. Impact of obturator nerve block on the short-term recurrence of superficial bladder tumors on the lateral wall. Urol J. 2014;11(1):1248-1252.
3. Akata T, Murakami J, Yoshinaga A. Life-threatening haemorrhage following obturator artery injury during transurethral bladder surgery: a sequel of an unsuccessful obturator nerve block. Acta Anaesthesiol Scand. 1999;43(7):784-788.

4. Bolat D, Aydogdu O, Tekgul ZT, et al. Impact of nerve stimulator-guided obturator nerve block on the short-term outcomes and complications of transurethral resection of bladder tumour: a prospective randomized controlled study. Can Urol Assoc J. 2015;9(11-12):E780-E784. doi:10.5489/cuaj.3149

5. Venkatramani V, Panda A, Manojkumar R, Kekre NS. Monopolar versus bipolar transurethral resection of bladder tumors: a single center, parallel arm, randomized, controlled trial. J Urol. 2014;191 (6):1703-1707. doi:10.1016/j.juro.2013.12.004

6. Aksu C. Ultrasound-guided obturator block experience from past year at Kocaeli University Hospital. Ăgrr J Turk Soc Algol. 2015. doi:10.5505/agri.2015.02360

7. Sinha SK, Abrams JH, Houle TT, Weller RS. Ultrasound-guided obturator nerve block: an interfascial injection approach without nerve stimulation. Reg Anesth Pain Med. 2009;34(3):261-264. doi:10.1097/AAP.0b013e3181a32c4d

8. Soong J, Schafhalter-Zoppoth I, Gray AT. Sonographic imaging of the obturator nerve for regional block. Reg Anesth Pain Med. 2007;32(2):146-151. doi:10.1016/j.rapm.2006.10.012

9. Fujiwara Y, Sato Y, Kitayama M, Shibata Y, Komatsu T, Hirota K. Obturator nerve block using ultrasound guidance. Anesth Analg. 2007;105(3):888-889. doi:10.1213/01.ane.0000268517.37921.ef

10. Anagnostopoulou S, Kostopanagiotou G, Paraskeuopoulos T, Chantzi C, Lolis E, Saranteas T. Anatomic variations of the obturator nerve in the inguinal region: implications in conventional and ultrasound regional anesthesia techniques. Reg Anesth Pain Med. 2009;34 (1):33-39. doi:10.1097/AAP.0b013e3181933b51 
11. Taha AM. Brief reports: ultrasound-guided obturator nerve block: a proximal interfascial technique. Anesth Analg. 2012;114 (1):236-239. doi:10.1213/ANE.0b013e318237fb40

12. Akkaya T, Ozturk E, Comert A, et al. Ultrasound-guided obturator nerve block: a sonoanatomic study of a new methodologic approach. Anesth Analg. 2009;108(3):1037-1041. doi:10.1213/ane.0b013e3 $181966 \mathrm{f03}$

13. Lin JA, Nakamoto T, Yeh SD. Ultrasound standard for obturator nerve block: the modified Taha's approach. Br J Anaesth. 2015;114 (2):337-339. doi:10.1093/bja/aeu467

14. Yoshida T, Nakamoto T, Kamibayashi T. Ultrasound-guided obturator nerve block: a focused review on anatomy and updated techniques. Biomed Res Int. 2017;2017:1-9. doi:10.1155/2017/ 7023750

15. Dupont WD, Plummer WD Jr. Power and sample size calculations for studies involving linear regression. Control Clin Trials. 1998;19 (6):589-601.
16. Newman B, McCarthy L, Thomas PW, May P, Layzell M, Horn K. A comparison of pre-operative nerve stimulator-guided femoral nerve block and fascia iliaca compartment block in patients with a femoral neck fracture. Anaesthesia. 2013;68(9):899-903. doi:10.1111/anae.12321

17. Lang SA, Yip RW, Chang PC, Gerard MA. The femoral 3 in 1 block revisited. J Clin Anesth. 1993;5(4):292-296.

18. Nielsen TD, Moriggl B, Soballe K, Kolsen-Petersen JA, Borglum J, Bendtsen TF. A cadaveric study of ultrasound-guided subpectineal injectate spread around the obturator nerve and its hip articular branches. Reg Anesth Pain Med. 2017;42(3):357-361. doi:10.1097/ AAP.0000000000000587

19. Tatlisen A, Sofikerim M. Obturator nerve block and transurethral surgery for bladder cancer. Minerva Urol Nefrol. 2007;59(2):137-141.

20. Mihara T, Itoh H, Hashimoto K, Goto T. Trans-resectoscope stimulation predicts the need to block adductor response during bladder tumor resection. Anesth Analg. 2013;117(3):740-744. doi:10.1213/ ANE.0b013e3182a07063

\section{Publish your work in this journal}

Cancer Management and Research is an international, peer-reviewed open access journal focusing on cancer research and the optimal use of preventative and integrated treatment interventions to achieve improved outcomes, enhanced survival and quality of life for the cancer patient.
The manuscript management system is completely online and includes a very quick and fair peer-review system, which is all easy to use. Visit http://www.dovepress.com/testimonials.php to read real quotes from published authors. 